\title{
Entertaining accurate treatment expectations while suffering from chronic pain: an exploration of treatment expectations and the relationship with patient- provider communication
}

\author{
Bianca Wiering $^{1 *}\left(\mathbb{D}\right.$, Dolf de Boer ${ }^{2}$, Maarten Krol ${ }^{2}$, Hilda Wieberneit-Tolman ${ }^{3}$ and Diana Delnoij ${ }^{1}$
}

\begin{abstract}
Background: Accurate patient expectations are important to optimise treatment success, especially for complex conditions such as chronic pain. Communication may be the key to managing patient expectations. This study aimed to explore whether health care provider communication influences patient expectations and which communication aspects are most important.

Methods: We conducted secondary analyses on data that had been collected between September and November 2012. 2603 patients suffering from chronic pain were invited to complete a survey.

Results: Although $69.9 \%$ of patients achieved or surpassed their treatment goal, 30.2\% of patients were unsatisfied. Even though overall health care provider communication and shared decision making were unrelated to patient expectations, several affective communication aspects were related. These aspects were attentive listening, taking enough time, building patient's trust in the physician's competence and giving patients the feeling that the physician is doing all he or she can ( $p$ 's $<0.05$ ).
\end{abstract}

Conclusions: Even though treatment goals are not always explicitly discussed, patients still form expectations regarding treatment outcomes. Affective communication may be more important for managing patient expectations than sharing information. Building a good therapeutic relationship by showing affective communication may be important to increase the accuracy of patient expectations.

Keywords: Treatment expectations, Treatment goals, Health care provider communication, Shared decision making, Patient reported experience measure

\section{Background}

Patient expectations of treatment outcomes can be very important for achieving optimal treatment success. Patient expectations can not only influence satisfaction after treatment, [1-3] but also patient outcomes [4-6], the number of return visits [7] and self-care [6]. However, research shows that many patients harbour inaccurate expectations regarding

\footnotetext{
* Correspondence: biancawiering@gmail.com

${ }^{1}$ Tranzo (Scientific Centre for Transformation in Care and Welfare), Tilburg University, PO Box 90153, 5000, LE, Tilburg, The Netherlands

Full list of author information is available at the end of the article
}

treatment outcomes [8-11]. The term inaccurate or unrealistic expectations is used to describe expectations that do not match with what is expected to be achievable with treatment $[10,12,13]$. Patients' expectations regarding treatment goals can differ widely from those of their physicians [14]. Ensuring that patients entertain accurate expectations of treatment may be especially important for medically complex chronic conditions. Patients suffering from these conditions may need treatment for a long time [15], treatment is often based on self-medication $[16,17]$ and treatment goals may be less clear. Accurate

(c) The Author(s). 2018 Open Access This article is distributed under the terms of the Creative Commons Attribution 4.0 International License (http://creativecommons.org/licenses/by/4.0/), which permits unrestricted use, distribution, and reproduction in any medium, provided you give appropriate credit to the original author(s) and the source, provide a link to the Creative Commons license, and indicate if changes were made. The Creative Commons Public Domain Dedication waiver (http://creativecommons.org/publicdomain/zero/1.0/) applies to the data made available in this article, unless otherwise stated. 
expectations may prevent these patients from getting discouraged, which may for instance influence medication adherence [6].

A good example of a complex chronic condition is chronic pain. A large survey of 50,000 respondents originating from 15 European countries and Israel showed that as many as one in five adults in Europe may be suffering from chronic pain [15]. Many patients suffer from chronic pain for a number of years $[15,18]$. Chronic pain may affect patients' emotional well-being [15, 19], physical functioning [20], social activities and work [15, 21]. There are many treatment options available, such as anti-inflammatory agents, opioid analgesics, and physical therapy [18, $22,23]$. However, it is not uncommon that treatment is insufficient to treat the pain [15, 24, 25]. For these patients, treatment goals can range from easing or stabilising their pain, to a slower deterioration, or learning to deal with the condition [22, 23]. Even though a cure may not be achievable, a good match between patient expectations and outcomes has been shown to improve patients' satisfaction [22]. This makes the management of patient expectations a fairly effective way to optimise patients' satisfaction levels with treatment.

One way to improve the accuracy of patient expectations may be by improving patient-provider communication. Active engagement in shared decision making, patient education or discussing patients expectations could perhaps help physicians clarify what can be expected from treatment and address misconceptions $[1,14]$. However, many patients fail to discuss their expectations [26] and identifying patients' expectations seems to be a challenge for physicians [27, 28]. Furthermore, it is not clear which aspects of communication may be of importance to improve the accuracy of patient expectations and treatment goals.

More knowledge is needed about whether health care provider communication may help to achieve more accurate patient expectations, and if that is the case, which aspects of communication contribute. Although health care providers' views may also be important for identifying aspects of care which benefit the accuracy of patient expectations, in the present study only the patients' views were included. By exploring patients' treatment expectations in relation to patients' views on communication during consultations, this study aimed to explore the role of health care provider communication and the different aspects of communication in achieving more accurate treatment goals.

Our research questions were:

- Do patients entertain accurate treatment expectations?
- Is better health care provider communication associated with more accurate treatment expectations?

- Which health care provider communication aspects are important in clarifying what patients can expect from treatment?

\section{Methods}

\section{The umbrella study}

This study is based on secondary analysis of data from a bigger study initiated by a Dutch umbrella organisation 'Pijn Platform Nederland', with the aim of, among other things, developing a patient reported experience measure [29]. Three of the five current authors were part of the umbrella study. The umbrella study was responsible for recruiting all participants and collecting the data. The following participants and procedure sections are descriptions of how the umbrella study recruited participants and collected data.

\section{Participants}

Four Dutch patient organisations for patients suffering from chronic pain each supplied about 600 randomly chosen member addresses for this study. One patient organisation contacted their 600 randomly chosen members first to gain approval before sharing the addresses. 182 members of this organisation allowed the sharing of their addresses. In the end, 2603 patients suffering from chronic pain were invited to fill in a questionnaire during the period of September-November 2012.

\section{Procedure}

A formal ethical board review was not required for this study, as it did not fall under the Dutch Medical Research Involving Human Subjects Act (WMO) [30]. The National Health Care Institute guidelines were applied during data collection. The guidelines cover privacy and informed consent [31]. Participation was voluntary and anonymous. Patients received an invitation letter either by e-mail or by post from the Dutch umbrella organisation, the website address of the survey, login details and a card that could be sent back if one did not wish to participate. A reminder or thank you note was sent a week after the invitation letter. After 2 weeks, a second reminder was sent, accompanied by a paper version of the survey or thank you note. A fourth and final reminder or a thank you note was sent after 3 weeks.

\section{Measures}

The survey included questions on background characteristics, a patient reported outcome question, and a patient reported experience measure (PREM) [29]. The background characteristics used in this study were age, gender, overall health, and educational attainment. 
Table 1 The first part of the construction of the dependent variable: the merger of the responses to the patient reported outcome question and the treatment goals. $(N=585)$

\begin{tabular}{llll}
\hline & $\begin{array}{l}\text { Goal is } \\
\text { complete } \\
\text { recovery }\end{array}$ & $\begin{array}{l}\text { Goal is } \\
\text { decrease in } \\
\text { pain }\end{array}$ & $\begin{array}{l}\text { Goal is } \\
\text { to stabilise } \\
\text { pain }\end{array}$ \\
\hline $\begin{array}{l}\text { The pain has gone } \\
\begin{array}{l}\text { The pain has } \\
\text { (slightly) decreased }\end{array}\end{array}$ & $9^{\mathrm{b}}$ & $1^{\mathrm{c}}$ & $0^{\mathrm{c}}$ \\
$\begin{array}{l}\text { The pain is stable } \\
\begin{array}{l}\text { The pain has } \\
\text { (slightly) increased }\end{array}\end{array}$ & $6^{\mathrm{a}}$ & $238^{\mathrm{b}}$ & $110^{\mathrm{c}}$ \\
\hline
\end{tabular}

${ }^{\mathrm{a}} \mathrm{Goal}$ was not achieved

${ }^{\mathrm{b}} \mathrm{Goal}$ was achieved

${ }^{\mathrm{C}}$ Results were better than treatment goal

Several questions and measurement instruments were used to establish how accurate patient expectations were compared to treatment goals (Tables 1 and 2). The first question concerns a patient reported outcome question. The question asked patients whether their level of pain had changed since starting treatment. Answer options ranged from 1 'Yes, the pain has gone', to 6 'Yes, the pain has gotten worse'.

Further questions concerning treatment goals and expectations which were part of a PREM [29] were also included. Patients were asked what the goal of their treatment was. Answer options ranged from 1 'Complete recovery', to 4 'Learning to cope with the pain'. Patients were also asked whether the treatment results matched their expectations. Answer options ranged from 1 'Not at all', to 4 'Yes'. Finally, patients who did not answer 'Yes' to the former question were asked why the results did not match their expectations. Answer options were 'The result was better than I expected', and 'The result was not as good as I expected'.

Finally, communication was measured using two subscales from the PREM concerning health care professional communication and shared decision making [29] (Table 3). Patients rated their experiences with health care provider communication from 1 'Never', to 4 'Always'.

\section{Statistical analyses}

Raw data files from the umbrella study were used to conduct the analyses. Participant and pain characteristics, patient expectations and treatment goals were described using univariate analyses. To calculate whether patients' expectations were accurate compared to the treatment goals in light of the treatment results, the questions regarding whether the results matched patients' expectations and why the results did not match their expectations were combined. This resulted in a variable ranging from 'The results were not as good as expected', to 'The results were better than expected'. Furthermore, treatment results (i.e. the answers to the patient reported outcome question) and treatment goals were compared to establish whether the treatment goal was achieved. As the patient reported outcome question only gave answer options describing pain progression or relief, the treatment goal answer option 'Learning to cope with the pain' was removed from analysis. This resulted in a variable ranging from 'Goal was not achieved', to 'Results were better than treatment goal' (Table 1). Both these variables were combined to create a variable describing how accurate expectations were (for example: results were better than treatment goal, but patient still expected better. In such a case, the patient entertained too high expectations) (Table 2). The term accuracy is used to describe whether patients expected the result that should have been achieved based on the treatment goals. To explore any associations between communication and treatment expectations, partial Pearson correlations were used ${ }^{1}$. Variables included in the correlation analysis were the variable describing how accurate treatment expectations were (i.e. too low expectations, accurate expectations and too high expectations), and the subscales health care provider communication (an average of 7 items; Cronbach's alpha $=.92$ ) and shared decision making (an average of 4 items; Cronbach's alpha $=.81$ ). The subscales were based on principal component analysis. Principal component analysis was conducted for the umbrella study and was repeated for this study. As factor analysis showed that the

Table 2 The second part of the construction of the dependent variable: the accuracy of patient expectations (too low expectations, accurate expectations and too high expectations). $(N=469)$

\begin{tabular}{|c|c|c|c|c|c|c|c|c|c|c|c|c|}
\hline & \multicolumn{4}{|c|}{ Goal was not achieved } & \multicolumn{4}{|c|}{ Goal was achieved } & \multicolumn{4}{|c|}{ Results were better than goal } \\
\hline & $\begin{array}{l}\text { Pain } \\
\text { increased }\end{array}$ & $\begin{array}{l}\text { Pain is } \\
\text { stable }\end{array}$ & $\begin{array}{l}\text { Pain } \\
\text { decreased }\end{array}$ & $\begin{array}{l}\text { Pain has } \\
\text { gone }\end{array}$ & $\begin{array}{l}\text { Pain } \\
\text { increased }\end{array}$ & $\begin{array}{l}\text { Pain is } \\
\text { stable }\end{array}$ & $\begin{array}{l}\text { Pain } \\
\text { decreased }\end{array}$ & $\begin{array}{l}\text { Pain has } \\
\text { gone }\end{array}$ & $\begin{array}{l}\text { Pain } \\
\text { increased }\end{array}$ & $\begin{array}{l}\text { Pain is } \\
\text { stable }\end{array}$ & $\begin{array}{l}\text { Pain } \\
\text { decreased }\end{array}$ & $\begin{array}{l}\text { Pain has } \\
\text { gone }\end{array}$ \\
\hline $\begin{array}{l}\text { Patient expected } \\
\text { more }\end{array}$ & $29^{b}$ & $54^{b}$ & $12^{b}$ & 0 & 0 & $23^{c}$ & $52^{c}$ & $1^{c}$ & 0 & 0 & $23^{c}$ & 0 \\
\hline $\begin{array}{l}\text { Patient expectations } \\
\text { matched results }\end{array}$ & $6^{a}$ & $11^{a}$ & $13^{a}$ & 0 & 0 & $22^{b}$ & $51^{b}$ & $1^{b}$ & 0 & 0 & $24^{c}$ & 0 \\
\hline Patient expected less & 0 & $8^{a}$ & $8^{a}$ & 0 & 0 & $4^{a}$ & $79^{a}$ & $5^{a}$ & 0 & 0 & $42^{b}$ & $1^{b}$ \\
\hline
\end{tabular}

${ }^{a}$ Too low expectations compared to treatment goals and treatment results

${ }^{\mathrm{b}}$ Accurate expectations compared to treatment goals and treatment results

${ }^{\mathrm{C}}$ Too high expectations compared to treatment goals and treatment results 
Table 3 Patient and pain characteristics. $(N=886)$

\begin{tabular}{|c|c|c|}
\hline & $\mathrm{N}(\%)$ & Mean (SD) \\
\hline \multicolumn{3}{|l|}{$\overline{\text { Age }}$} \\
\hline 18 to 24 years & $8(.9 \%)$ & \\
\hline 25 to 34 years & $40(4.6 \%)$ & \\
\hline 35 to 44 years & $100(11.4 \%)$ & \\
\hline 45 to 54 years & $246(28.0 \%)$ & \\
\hline 55 to 64 years & $274(31.2 \%)$ & \\
\hline 65 to 74 years & $142(16.2 \%)$ & \\
\hline 75 years or older & $68(7.7 \%)$ & \\
\hline Sex (Female) & $633(72.9 \%)$ & \\
\hline \multicolumn{3}{|l|}{ Educational attainment } \\
\hline University (MSc/BSC) & $61(7.2 \%)$ & \\
\hline Higher vocational education (BSc) & $238(28.2 \%)$ & \\
\hline Middle vocational education & $188(22.2 \%)$ & \\
\hline High school/ secondary education & $337(39.9 \%)$ & \\
\hline$<$ High school level & $21(2.5 \%)$ & \\
\hline \multicolumn{3}{|l|}{ Cause of pain } \\
\hline Accident & $254(30.9 \%)$ & \\
\hline Disease & $168(20.4 \%)$ & \\
\hline Surgical procedure & $78(9.5 \%)$ & \\
\hline Unknown & $178(21.7 \%)$ & \\
\hline Other & $144(17.5 \%)$ & \\
\hline Duration of pain in years (until 2012) & & $14.9(11.9)$ \\
\hline \multicolumn{3}{|l|}{ Treatment type } \\
\hline Medication & $114(17.7 \%)$ & \\
\hline Injections & $47(7.3 \%)$ & \\
\hline Transcutaneous electrical nerve stimulation & $18(2.8 \%)$ & \\
\hline Surgical procedure & $18(2.8 \%)$ & \\
\hline Physiotherapy & $265(41.2 \%)$ & \\
\hline Cesar/Mensendieck practice therapy & $17(2.6 \%)$ & \\
\hline Psychological support & $27(4.2 \%)$ & \\
\hline Other & $99(15.4 \%)$ & \\
\hline \multicolumn{3}{|l|}{ Treatment goal } \\
\hline Complete recovery & $53(7.7 \%)$ & \\
\hline Decrease in pain & $347(50.7 \%)$ & \\
\hline Stabilising pain & $187(27.3 \%)$ & \\
\hline Learning to cope with pain & $65(9.5 \%)$ & \\
\hline Other & $28(4.1 \%)$ & \\
\hline
\end{tabular}

Cronbach's alpha was significantly higher if one item was deleted from the shared decision making scale [29], the item was removed from analysis. To further explore which communication aspects are specifically associated with treatment expectations, all communication items were entered separately in a second partial correlation analysis. Furthermore, all analyses were controlled for sex, age, overall health and educational attainment. Analyses were performed using SPSS 22.0 [32].

\section{Results \\ Response}

Of the 2603 patients invited to participate, 23 patients could not be contacted because the address was unknown, or the patient had passed away. 371 patients indicated that they would not take part because they did not currently experience pain symptoms. Of the remaining 2209 patients eligible to participate, $894 \mathrm{pa}-$ tients completed the questionnaire. This meant a response rate of $40.5 \%$. Finally, the data of 8 patients were removed because they indicated that they did not complete the questionnaire themselves. A total of 886 patients' results were included in the analyses (Fig. 1).

\section{Participants}

The age group 55 to 64 years was most prevalent among the participants (Table 3). Most participants were female (72.9\%) and completed secondary education (39.9\%). Many participants suffered from pain for a long time (Mean: 14.9 years; SD: 11.9 years). Common causes of pain were accidents (30.9\%) and disease (20.4\%). Additionally, many participants did not know what caused their chronic pain (21.7\%). Most participants received physiotherapy (41.2\%) or medication (17.7\%).

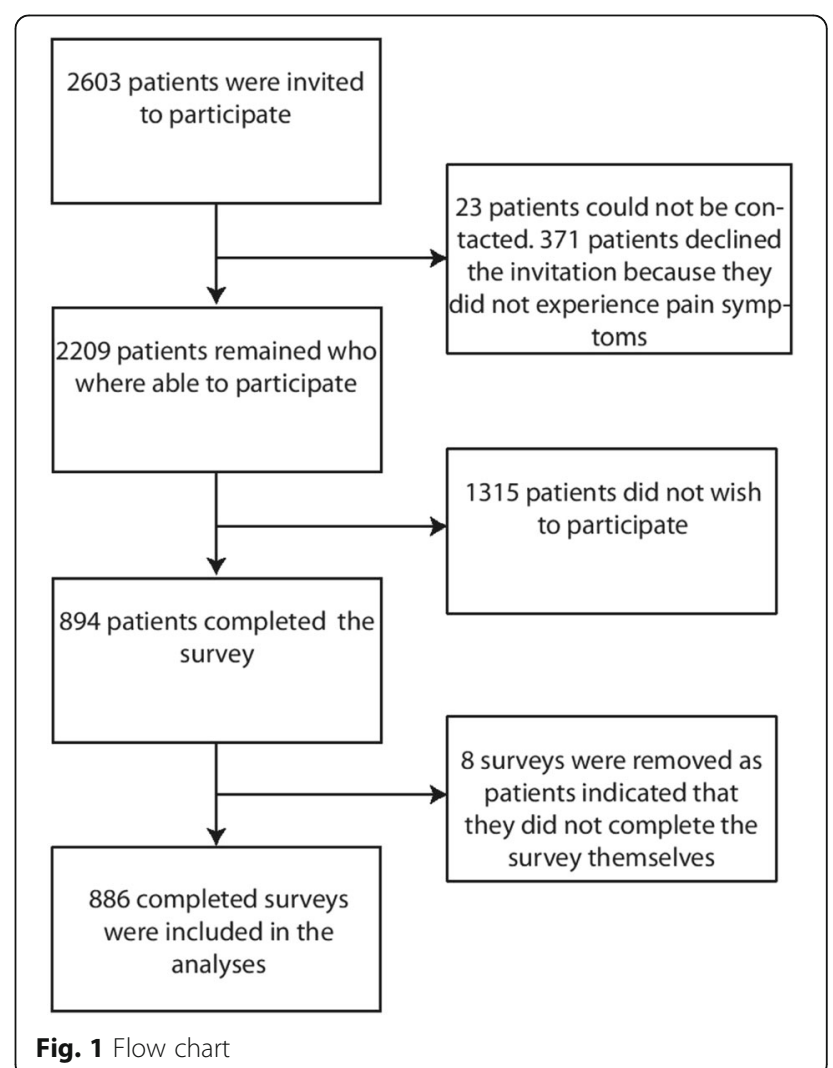




\section{Patients' expectations of treatment}

Participants indicated that they mostly received treatment with the aim to decrease $(50.7 \%)$ or stabilise $(27.3 \%)$ their pain level. For many patients the pain did stabilise (26\%), or even decreased to a greater (29.4\%) or lesser extend (34\%). However, about $41.8 \%$ of patients indicated that they had expected better results, while $33.3 \%$ of patients achieved a better result than they expected. If the results are compared to the treatment goals as described by the patients, there is still a gap between results and expectations. Although $69.9 \%$ of patients achieved or surpassed their treatment goal, and $39.9 \%$ of patients did not expect such a great improvement, $30.2 \%$ of the patients were still unsatisfied.

\section{Communication and expectations}

Although in only $29.9 \%$ of cases treatment goals were discussed in full, just 4 patients indicated that they truly did not know what the goal of their treatment was. Apparently patients do not need much discussion of treatment goals to have an idea about what the goal should be. This is further reflected in the lack of an association between communication and how accurate patients' expectations are compared to these goals. Both health care provider communication $(r=-.10, p=.08)$ and shared decision making $(r=-.06, p=.27)$ were unrelated to the accuracy of patients' expectations (i.e. whether patients' expectations match with the treatment goals) (Table 4). However, although overall communication may not be related to patient expectations, certain aspects of communication were related to the level of accuracy of patient expectations. For several communication aspects lower scores were related to too high expectations (i.e. Patients expected better results, even though the treatment goal was achieved or surpassed). Important communication aspects were attentive listening $(r=-.11$, $p=.05)$, time available for the patient $(r=-.14, p=.01)$, whether patients trust their health care provider's competence $(r=-.12, p=.03)$, and whether patients felt that their health care provider had done all he or she could $(r=-.18, p=.00)$.

\section{Discussion and conclusion \\ Discussion}

For conditions such as chronic pain, treatments are often not a cure and treatment goals are not always clear cut. However, accurate expectations of treatment may increase patients' satisfaction [22]. This study therefore first aimed to explore whether patients have a clear idea of what should be achieved with treatment. The present study found that although treatment goals were seldom fully discussed, almost all patients had ideas about what the goal of their treatment was. However, even if this treatment goal was achieved or surpassed, many patients still entertained higher or lower expectations than the achieved result. Perhaps imagining what it would feel like to achieve a treatment goal may still be fairly difficult for patients. Inaccurate expectations are fairly common among patients, for example among patients undergoing surgery $[10,11]$. However, surgery usually consists of one operation with the aim of improving health aspects such as functioning [33], pain level [11] or weight [10, 34]. Treatments of chronic conditions such as chronic pain are not always given with the aim

Table 4 The association between communication aspects and the level of patient expectations compared to treatment goals (i.e. Too low, accurate or too high expectations). $(N=315)$

\begin{tabular}{|c|c|c|}
\hline & Level & $\mathrm{d}$ to Treatment goals \\
\hline & $\bar{R}$ & $P$ \\
\hline Overall health care provider communication & -.10 & .08 \\
\hline Shared decision making & -.06 & .27 \\
\hline The health care provider listened carefully & -.11 & .05 \\
\hline The health care provider spent enough time on the patient & -.14 & .01 \\
\hline The health care provider took the patient seriously & -.10 & .07 \\
\hline The patient trusts the health care providers' competence & -.12 & .03 \\
\hline The health care provider paid attention to emotional problems & .05 & .39 \\
\hline The health care providers explained everything clearly & -.08 & .15 \\
\hline The health care provider has done all he or she could & -.18 & .00 \\
\hline The health care provider discussed what can be expected of treatment & -.02 & .78 \\
\hline The health care provider provided information on treatment options & -.07 & .20 \\
\hline The patient took part in the decision making process & -.06 & .31 \\
\hline $\begin{array}{l}\text { The health care provider took into account the patient's preferences } \\
\text { while deciding for a treatment }\end{array}$ & -.05 & .34 \\
\hline
\end{tabular}


to improve and may even only focus on coping [22, 23]. As possible outcomes are not limited to improvement and treatment outcomes may be uncertain, it is perhaps even more difficult to entertain accurate expectations.

As apparently not all patients seem to know what to expect from treatment, the present study tried to explore whether better health care provider communication may help achieve more accurate treatment expectations. This study found that although improving health care provider communication overall may not benefit the accuracy of patient expectations, several aspects of communications were found to be related to patient expectations. Perhaps the lack of influence from some communication aspects counterbalanced the few communication aspects which did have an effect on patients' expectations. More remarkable is the difference between the communication aspects which did not influence expectations and the communication aspects which did. Many of the communication aspects which were not significantly related to expectations concerned instrumental communication aspects. Instrumental communication focuses on the patient's cognitive need to be informed [35]. Important aspects of instrumental communication are gathering data by asking questions and providing information [36]. Due to its informative nature, one would expect that showing more instrumental communication would increase the accuracy of patient expectations. This, however, appears not to be the case. Instead, affective communication may be the key to accurate expectations. Affective communication focuses on building a therapeutic relationship between the health care provider and the patient [36]. In this case, the aspects of affective communication that seemed to matter centred around attentive listening, taking enough time, building patient's trust in the physician's competence, and giving patients the feeling that the physician is doing all he or she can. These communication aspects are often seen as important factors that contribute to the building of the patient's trust in a health care provider [37,38]. It is perhaps not very surprising that patients are more willing to adhere to treatment recommendations if they trust their health care provider [37]. Perhaps this is also the case for treatment expectations. Possibly the affective communication contributes to the building of a level of trust which ensures that patients more easily trust what their health care provider tells them.

However, there appears to be a fine line between good communication, too much communication and too little. Low scores on the important communication aspects were related to expectations that were too high, while high scores were related to too low expectations. Apparently the perfect level of communication is somewhere in the middle. The relationship between low patient expectations and good affective communication may be a sign that it worries patients if health care providers show too much empathy and therefore come across as concerned. Alternatively, research shows that patients usually entertain too high expectations to begin with [10, 11]. As patients are more likely to recall advice correctly if it has been discussed for longer [39], taking more time may have ensured that patients better recall their physician's advice and lower their expectations accordingly. The relationship between too high expectations and little affective communication may be due to cognitive dissonance, where individuals change or distort two dissonant ideas to make them more consonant [40]. In this case, patients' disappointment with the treatment results may have coloured their recollection of their health care provider's communication.

\section{Limitations}

There are several limitations that need to be taken into account. First, although the health care providers' views on treatment goals and communication may be equally important to identify the accuracy of patient expectations and important communication aspects, this study reports secondary analyses of data that only contained questionnaires completed by patients.

Second, the data used for the secondary analyses was collected in 2012. Although some of the data may be slightly outdated, research suggests that health care provider communication and especially psychosocial communication, have not improved much over time [41]. Furthermore, treatment for chronic pain is still considered ineffective for many patients [42]. As a cure is still unlikely for many patients, ensuring that patients entertain accurate expectations should still be a priority. It is therefore unlikely that the use of slightly older data has impacted the relevance of the study's results.

Third, research shows that patients have problems recalling what has been discussed after consultations $[9,39]$. These recall problems may also be applicable to recalling communication and treatment goals. Perhaps a more objective method may be to record the consultations [43].

Fourth, the response rate was fairly low and no data is available of the patients who did not respond. It is therefore not possible to compare the participant group to the non-response group to check the representativeness of the participant group.

Additionally, all participants were affiliated with organisations concerned with the condition of patients suffering from chronic pain. This also may have affected the representativeness of the participant group, as they were arguably more informed on the subject of pain treatment than random patients suffering from chronic pain.

\section{Practice implications}

The results of this study have several implications for chronic pain consultations and research. First, this study 
showed that patients feel that treatment goals are not always discussed during consultations. As patients still develop ideas about what should be achieved by undergoing a certain treatment, actively discussing treatment goals may be a useful start in clarifying what patients can expect.

Furthermore, even if patients achieved the treatment goals they indicated on the questionnaire, they still not always felt that their expectations were met. Perhaps they still had personal goals which were not achieved even after achieving their treatment goals, or possibly they are not sure how achieving the treatment goal should feel. Either way, it may be helpful to set and clarify treatment goals by using aids such as patient reported outcome measures. Scores on health dimensions may help patients to visualise and track their progress $[44,45]$.

Alternatively, physicians could personalise treatment goals by discussing with patients which activities that are influenced by pain the patient would like to be able to do again. For example, going out to dinner with friends after a work day, or going to the zoo with their children. The success of the treatment is measured by establishing to what extent the patient is able to do the activities. The activity should of course be achievable. This would not only help patients get a better grip on what could and should be achieved, make treatment goals more relevant to patients and raise awareness of when a goal has been achieved, it could also help physicians personalise treatment as part of a more person-centred approach [46]. Such a personal approach may help to further build on the therapeutic relationship. As our results show that communication focused on relationship building influences patients' expectations, personalising treatment may improve the accuracy of expectations not only via further clarification of treatment goals, but also via an increasingly good relationship.

Furthermore, the results show that there are some communication aspects which may influence how accurate patient expectations are. Apparently, affective communication aspects such as attentive listening, taking enough time, building patient's trust in the physician's competence, and giving patients the feeling that the physician is doing all he or she can may influence what patients expect from treatment. However, although studies concerning patient-physician communication call for an increase in behaviours such as taking enough time [47, 48], building trust [49] and listening [50], this study indicates that not only too little of these behaviours may have consequences, but also too much. Further research may be needed to investigate how an excess of positive communicative behaviours influences patient perspectives and outcomes.

Finally, theoretically [51] and empirically [52, 53], there is an association between patient expectations and patient satisfaction. In our study we have not measured satisfaction. We only know whether the patients considered their results better, similar or worse than they expected it to be. It is conceivable that chronic patients who consider their results better than expected, are also more satisfied. Future studies in this patient population could shed more light on this.

\section{Conclusion}

The goals of treatments meant to treat chronic pain are often not fully discussed with patients during consultations. Even though treatment goals may not be explicitly discussed by their physician, patients still form expectations regarding treatment outcomes. These expectations do not tend to be very accurate. Patients can entertain both too high and too low expectations. Even if their treatment goal has been achieved, patient expectations are not always fulfilled. Although overall health care provider communication and shared decision making do not appear to affect the accuracy of patients' expectations, several affective communication aspects may help patients achieve more accurate expectations. These communication aspects were attentive listening, taking enough time, building patient's trust in the physician's competence, and giving patients the feeling that the physician is doing all he or she can. Demonstrating the right level of these behaviours may be a balancing act, as both too much and too little may affect patient expectations for the worse. Further research is needed to investigate the effect of demonstrating too much of the above mentioned communication aspects. Furthermore, personalising treatment goals may help patients understand the treatment goals better and raise awareness of when treatment goals are achieved.

\section{Endnotes}

${ }^{1}$ Due to a low number of complete cases, partial correlations are reported in the present paper. However, similar results were obtained using ordinal logistic regression analysis.

\section{Abbreviations \\ PREM: Patient reported experience measure; WMO: Dutch Medical Research Involving Human Subjects Act}

\section{Acknowledgements}

We wish to thank the organisations Pijn Platform Nederland, Stichting PijnHoop, Nederlandse Vereniging van Rugpatiënten "de Wervelkolom" (NWR), Sarcoïdose Belangenvereniging Nederland and Whiplash Stichting Nederland.

\section{Authors' information (optional)}

Not applicable.

\section{Funding}

This study was funded by the National Health Care Institute. The National Health Care Institute did not have any role in the study design; in the 
collection, analysis and interpretation of data; in the writing of the manuscript; and in the decision to submit the manuscript for publication.

\section{Availability of data and materials}

The datasets used and analysed during the current study are available from the corresponding author on reasonable request.

\section{Authors' contributions}

HWT and MK were involved in the overall study design, the data collection and the writing process. BW, DD and DB were involved in the study design of this paper, the data analysis and the writing process. All authors have read and approved the manuscript.

\section{Ethics approval and consent to participate}

As our study concerned no personal issues, participants were not subjected to acts and the participants were consenting adults, no ethics approval was needed in the Netherlands. Participation was voluntary and anonymous. Patients received an invitation letter from the Dutch umbrella organisation. A card was included that could be sent back if one did not wish to participate.

\section{Consent for publication}

Participants were informed of the purposes of our study. Participation was voluntary and anonymous. No individual patient data is discussed.

\section{Competing interests}

The authors declare that they have no competing interests.

\section{Publisher's Note}

Springer Nature remains neutral with regard to jurisdictional claims in published maps and institutional affiliations.

\section{Author details}

${ }^{1}$ Tranzo (Scientific Centre for Transformation in Care and Welfare), Tilburg University, PO Box 90153, 5000, LE, Tilburg, The Netherlands. ${ }^{2}$ NIVEL (Netherlands institute for health services research), Utrecht, the Netherlands. ${ }^{3}$ Pijn Platform Nederland, Leiden, the Netherlands.

Received: 1 June 2018 Accepted: 27 August 2018 Published online: 11 September 2018

\section{References}

1. Pusic AL, Klassen AF, Snell L, Cano SJ, McCarthy C, Scott A, Cemal Y, Rubin $L R$, Cordeiro PG. Measuring and managing patient expectations for breast reconstruction: impact on quality of life and patient satisfaction. Expert Rev Pharmacoecon Outcomes Res. 2012;12(2):149-58.

2. Haddad FS, Garbuz DS, Chambers G, Jagpal T, Masri BA, Duncan CP. The expectations of patients undergoing revision hip arthroplasty. J Arthroplast. 2001;16(1):87-91.

3. Fisher C, Noonan V, Bishop P, Boyd M, Fairholm D, Wing P, Dvorak M. Outcome evaluation of the operative management of lumbar disc herniation causing sciatica. J Neurosurg Spine. 2004;100(4):317-24.

4. Wiering B, De Boer D, Delnoij D. Asking what matters: the relevance and use of patient reported outcome measures that were developed without patient involvement. Health Expect. 2017;6:1330-41.

5. Ronnberg K, Lind B, Zoega B, Halldin K, Gellerstedt M, Brisby H. Patients' satisfaction with provided care/information and expectations on clinical outcome after lumbar disc herniation surgery. Spine. 2007;32(2):256-61.

6. Iversen MD, Daltroy LH, Fossel AH, Katz JN. The prognostic importance of patient pre-operative expectations of surgery for lumbar spinal stenosis. Patient Educ Couns. 1998;34(2):169-78.

7. Macfarlane J, Holmes W, Macfarlane R, Britten N. Influence of patients' expectations on antibiotic management of acute lower respiratory tract illness in general practice: questionnaire study. Bmj. 1997;315(7117):1211-4.

8. Doyle C, Crump M, Pintilie M, Oza AM. Does palliative chemotherapy palliate? Evaluation of expectations, outcomes, and costs in women receiving chemotherapy for advanced ovarian cancer. J Clin Oncol. 2001; 19(5):1266-74

9. Wittmann D, He C, Coelho M, Hollenbeck B, Montie JE, Wood DP. Patient preoperative expectations of urinary, bowel, hormonal and sexual functioning do not match actual outcomes 1 year after radical prostatectomy. J Urol. 2011;186(2):494-9.
10. Kaly P, Orellana S, Torrella T, Takagishi C, Saff-Koche L, Murr MM. Unrealistic weight loss expectations in candidates for bariatric surgery. Surg Obes Relat Dis. 2008;4(1):6-10

11. Nilsdotter AK, Toksvig-Larsen S, Roos EM. Knee arthroplasty: are patients expectations fulfilled? A prospective study of pain and function in 102 patients with 5-year follow-up. Acta Orthop. 2009;80(1):55-61.

12. Shuman AL, Shapiro JP. The effects of preparing parents for child psychotherapy on accuracy of expectations and treatment attendance. Community Ment Health J. 2002;38(1):3-16.

13. Weeks JC, Catalano PJ, Cronin A, Finkelman MD, Mack JW, Keating NL, Schrag D. Patients' expectations about effects of chemotherapy for advanced cancer. N Engl J Med. 2012;367(17):1616-25.

14. Heisler M, Vijan S, Anderson RM, Ubel PA, Bernstein SJ, Hofer TP. When do patients and their physicians agree on diabetes treatment goals and strategies, and what difference does it make? J Gen Intern Med. 2003; 18(11):893-902

15. Breivik H, Collett B, Ventafridda V, Cohen R, Gallacher D. Survey of chronic pain in Europe: prevalence, impact on daily life, and treatment. Eur J Pain. 2006;10(4):287.

16. Turk DC. Clinical effectiveness and cost-effectiveness of treatments for patients with chronic pain. Clin J Pain. 2002;18(6):355-65.

17. Barlow J, Wright C, Sheasby J, Turner A, Hainsworth J. Self-management approaches for people with chronic conditions: a review. Patient Educ Couns. 2002;48(2):177-87.

18. Moulin DE, Clark AJ, Speechley M, Morley-Forster PK. Chronic pain in Canada-prevalence, treatment, impact and the role of opioid analgesia. Pain Res Manag. 2002;7(4):179-84

19. Turk DC, Dworkin RH, Revicki D, Harding G, Burke LB, Cella D, Cleeland CS, Cowan P, Farrar JT, Hertz S. Identifying important outcome domains for chronic pain clinical trials: an IMMPACT survey of people with pain. Pain 2008;137(2):276-85.

20. Turk DC, Dworkin RH, Allen RR, Bellamy N, Brandenburg N, Carr DB, Cleeland C, Dionne R, Farrar JT, Galer BS. Core outcome domains for chronic pain clinical trials: IMMPACT recommendations. Pain. 2003:106(3):337-45.

21. Glajchen M. Chronic pain: treatment barriers and strategies for clinical practice. J Am Board Fam Prac. 2001:14(3):211-8.

22. Frantsve LME, Kerns RD. Patient-provider interactions in the management of chronic pain: current findings within the context of shared medical decision making. Pain Med. 2007:8(1):25-35

23. Ashburn MA, Staats PS. Management of chronic pain. Lancet. 1999; 353(9167):1865-9.

24. van Tulder MW, Koes BW, Bouter LM. A cost-of-illness study of back pain in the Netherlands. Pain. 1995;62(2):233-40.

25. Green CR, Wheeler JR, LaPorte F, Marchant B, Guerrero E. How well is chronic pain managed? Who does it well? Pain Med. 2002;3(1):56-65.

26. Bell RA, Kravitz RL, Thom D, Krupat E, Azari R. Unsaid but not forgotten: patients' unvoiced desires in office visits. Arch Intern Med. 2001;161(16): 1977-84.

27. Rozenblum R, Lisby M, Hockey PM, Levtizion-Korach O, Salzberg CA, Lipsitz S, Bates DW. Uncovering the blind spot of patient satisfaction: an international survey. BMJ Qual Saf. 2011;20(11):959-65.

28. Marple RL, Kroenke K, Lucey CR, Wilder J, Lucas CA. Concerns and expectations in patients presenting with physical complaints: frequency, physician perceptions and actions, and 2-week outcome. Arch Intern Med. 1997:157(13):1482-8.

29. Krol M, Boer Dd, Plass A, Rademakers J: CQ-index module Pijn: meetinstrumentontwikkeling. Ervaringen met pijnbehandeling en pijnbeleving van chronische pijnpatiënten en ontwikkeling van de CQ-index module Pijn 2013

30. Central Committee on Research Involving Human Subjects (CCMO). Your research: Does it fall under the WMO? http://www.ccmo.nl/en/yourresearch-does-it-fall-under-the-wmo. Accessed 12 Oct 2016.

31. Zorginstituut Nederland. Handboek Eisen en Werkwijzen CQI metingen, Vol. 2017. https://www.zorginzicht.nl/kennisbank/Paginas/Handboek-Eisen-enWerkwijzen-CQI-metingen.aspx. Accessed 12 Oct 2016.

32. Corp. I: IBM SPSS Statistics for Windows, Version 22.0. In. Armonk, NY: IBM Corp.; 2013

33. Bachmeier C, March L, Cross M, Lapsley H, Tribe K, Courtenay B, Brooks P, Cost A, Group OP. A comparison of outcomes in osteoarthritis patients undergoing total hip and knee replacement surgery. Osteoarthr Cartil. 2001; 9(2):137-46. 
34. White MA, Masheb RM, Rothschild BS, Burke-Martindale CH, Grilo CM. Do patients' unrealistic weight goals have prognostic significance for bariatric surgery? Obes Surg. 2007;17(1):74-81.

35. Engel GL. How much longer must medicine's science be bound by a seventeenth century world view? Psychother Psychosom. 1992;57(1-2):3-16.

36. Tates K, Meeuwesen L, Bensing J, Elbers E. Joking or decision-making? Affective and instrumental behaviour in doctor-parent-child communication. Psychol Health. 2002;17(3):281-95.

37. Thom DH, Campbell B. Patient-physician trust: an exploratory study. J Fam Prac. 1997;44(2):169-76.

38. Fiscella K, Meldrum S, Franks P, Shields CG, Duberstein P, McDaniel SH, Epstein RM. Patient trust: is it related to patient-centered behavior of primary care physicians? Med Care. 2004:1049-55.

39. Flocke SA, Stange KC. Direct observation and patient recall of health behavior advice. Prev Med. 2004:38(3):343-9.

40. Festinger L. A theory of cognitive dissonance, vol. 2. Redwood City: Stanford university press; 1962.

41. Butalid L, Verhaak PF, Bensing JM. Changes in general practitioners' sensitivity to patients' distress in low back pain consultations. Patient Educ Couns. 2015;98(10):1207-13.

42. Walter FM, Mills K, Mendonça SC, Abel GA, Basu B, Carroll N, Ballard S, Lancaster J, Hamilton W, Rubin GP. Symptoms and patient factors associated with diagnostic intervals for pancreatic cancer (SYMPTOM pancreatic study): a prospective cohort study. Lancet Gastroenterol Hepatol. 2016;1 (4):298-306.

43. Tattersall MH, Butow PN. Consultation audio tapes: an underused cancer patient information aid and clinical research tool. Lancet oncol. 2002;3(7): 431-7.

44. Snyder CF, Aaronson NK, Choucair AK, Elliott TE, Greenhalgh J, Halyard MY, Hess R, Miller DM, Reeve BB, Santana M. Implementing patient-reported outcomes assessment in clinical practice: a review of the options and considerations. Qual Life Res. 2012;21(8):1305-14.

45. Reuben DB, Tinetti ME. Goal-oriented patient care-an alternative health outcomes paradigm. N Engl J Med. 2012;366(9):777-9.

46. Baker A. Crossing the quality chasm: a new health system for the 21st century. BMJ. 2001;323(7322):1192.

47. Gross DA, Zyzanski SJ, Borawski EA, Cebul RD, Stange KC. Patient satisfaction with time spent with their physician. J Fam Pract. 1998;47(2):133-8.

48. Ogden J, Bavalia K, Bull M, Frankum S, Goldie C, Gosslau M, Jones A, Kumar S, Vasant K. "I want more time with my doctor": a quantitative study of time and the consultation. Fam Pract. 2004;21(5):479-83.

49. Lee $Y$-Y, Lin JL. The effects of trust in physician on self-efficacy, adherence and diabetes outcomes. Soc Sci Med. 2009;68(6):1060-8.

50. Lang F, Floyd MR, Beine KL. Clues to patients' explanations and concerns about their illnesses: a call for active listening. Arch Fam Med. 2000;9(3):222.

51. Sixma HJ, Kerssens JJ, Cv C, Peters L. Quality of care from the patients' perspective: from theoretical concept to a new measuring instrument. Health Expect. 1998; 1 (2):82-95.

52. Rao JK, Weinberger M, Kroenke K. Visit-specific expectations and patientcentered outcomes: a literature review. Arch Fam Med. 2000:9(10):1148.

53. Gheorghe IR, Gheorghe C-M, Purcărea VL. Measuring the perceived quality of ophthalmology services in private organizations. A marketing perspective. Rom J Ophthalmol. 2018;62(1):54.

Ready to submit your research? Choose BMC and benefit from:

- fast, convenient online submission

- thorough peer review by experienced researchers in your field

- rapid publication on acceptance

- support for research data, including large and complex data types

- gold Open Access which fosters wider collaboration and increased citations

- maximum visibility for your research: over $100 \mathrm{M}$ website views per year

At BMC, research is always in progress.

Learn more biomedcentral.com/submissions 